\title{
Thermomechanical Analysis of a Thermal Protection System with Defects and Heat Shorts
}

\author{
Wei H. $\mathrm{Ng}^{1}$, Peretz P. Friedmann ${ }^{2}$, Anthony M. Waas ${ }^{3}$ \\ Department of Aerospace Engineering \\ University of Michigan \\ Ann Arbor, Michigan 48109-2140 \\ Email: peretzf@umich.edu
}

\begin{abstract}
The thermomechanical behavior of damaged space shuttle tile thermal protection system is determined using the finite element method. The relative effects of damage on the thermal protection capability and the induced thermal stresses in the TPS are determined by comparing the thermal and structural response of the damaged configurations with the undamaged configurations. The TPS, consisting of 3 components (the LI-900 tile, the strain isolation pad and the underlying structure), is modeled as a discrete three-layer structure. The TPS is subjected to the re-entry heating and pressure profile of the Access to Space vehicle, and the transient temperature distribution and the resultant thermal stresses in the system are computed. Three different sizes of damage having diameters 0.5 ”, 1" and 1.5”, based on hypervelocity impact, are considered. The validity of the simplifying assumptions used in a recent study is systematically examined. Some of these assumptions are relaxed and their effects on the system response are studied in the present work. The effect of damage location on the overall behavior of the TPS is also examined. Damage changes the surface properties of the tile and increases the surface area exposed to heating. It significantly reduces the radiation heat loss from the surface of the tile, resulting in elevated temperatures in the TPS. The elevated temperatures, with the stress concentrations introduced by the damage increases the thermal stresses significantly. Results suggest that the damage considered is capable of raising the maximum temperature in the tile to beyond its melting point and may cause structural failure.
\end{abstract}

\section{Nomenclature}

$C \quad=$ Specific Heat

$D \quad=\quad$ Diameter and depth of damage in TPS

E $\quad$ = Young's modulus

$k=$ Thermal conductivity

$P \quad=$ Pressure

$q_{\text {ATS }} \quad=$ Heat flux profile of the ATS vehicle

$q_{1}, q_{2} \quad=$ Heat flux boundary conditions used in analyses

$r, z=$ Spatial coordinates for the axisymmetric configurations

$\mathrm{S}_{\mathrm{d}} \quad=$ Tile top surface in damaged region

$\mathrm{S}_{\mathrm{u}} \quad=$ Tile top surface in undamaged region

$T \quad=$ Temperature

$u_{i} \quad=\quad$ Displacement in the $i$-direction

\footnotetext{
${ }^{1}$ Ph.D. Candidate

${ }^{2}$ François-Xavier Bagnoud Professor, Fellow AIAA, AHS

${ }^{3}$ Professor, Associate Fellow, AIAA
} 


$\begin{array}{ll}x, y, z & =\text { Spatial coordinates for the square configurations } \\ \alpha & =\text { Coefficient of thermal expansion (CTE) } \\ \delta & =\text { Offset distance of damage from the center } \\ v & =\text { Poisson's ratio } \\ \rho & =\text { Density }\end{array}$

\section{Introduction and Problem Statement}

NE of the critical technologies required for hypersonic vehicles is the thermal protection system(TPS). The TPS protects the vehicle and its payload from the high temperatures generated by the severe aerodynamic heating. While stability at high temperatures is a primary factor in the selection of materials for the TPS, other operational requirements, like costs, weight efficiency and thermal compatibility with underlying structure, are also major concerns. For reusable launch vehicles (RLV), which have to survive multiple launches, the TPS has to withstand not only thermal loads, but also mechanical loads as well as harsh chemical environments, repeatedly without failure. The multitude of these conflicting requirements imposes some form of compromise, resulting in different TPS's that have been developed. Scotti, Clay and Rezin ${ }^{1}$ present an overview of the structural and material technologies that are currently in use, and could be potential future candidates for TPS in RLV's.

A variety of TPS have been studied analytically and experimentally. Most studies focus on TPS found on NASA's Space Shuttle, which is a first generation reusable spacecraft. Ko and Jenkins ${ }^{2}$ analyzed the Space Shuttle tile using a one-dimensional temperature profile across the tile's thickness. Sawyer ${ }^{3}$ investigated the strains developed in the shuttle tile due to aerodynamic loads and substructure deformations. Experimental verifications of the shuttle tile performance were carried out by Moser and Schneider, ${ }^{4}$ as well as Cooper et. al. ${ }^{5}$ Operational performance of the TPS obtained from flight tests of the shuttle Columbia was evaluated by Ried et. al., ${ }^{6}$ Dotts, Smith and Tillian, ${ }^{7}$ and Neuenschwander, Mcbride and Armour. ${ }^{8}$ Other TPS, not used on the shuttle, have also been considered. Shideler et. al. ${ }^{9}$ performed several analytical and experimental tests on the multiwall TPS. Milos and Squire ${ }^{10}$ conducted a finite element (FE) analysis of the thermal protection system for the X-34 leading edge. Shideler Webb and Pittman ${ }^{11}$ conducted verification tests on newer TPS concepts, which are less fragile than those currently used on the space shuttle. Thermal and structural FE analyses of an advanced metallic TPS were conducted by Blosser et. al. ${ }^{12}$

In a recent study ${ }^{13}$, the authors of this paper examined the thermomechanical behavior of a TPS that consists of the LI-900 high temperature reusable surface insulation tile and a strain isolation pad (SIP) attached to the underlying structure, which resembles approximately a portion of the space shuttle TPS as depicted in Figure 1.

Two configurations: a square configuration (Figure 2) which resembles the actual configuration and an axisymmetric configuration (Figure 3) were considered in Ref. 13. The damage profile shown in Figure 3, is based on the so-called "hypervelocity impact" ${ }^{\text {"4 }}$ which produces an actual damage profile illustrated in Figure 4 . The actual damage in the models is replaced by an approximate damage profile that consists of a cylindrical hole, ending with a spherical cap. The depth of the damaged portion is equal to its diameter. The axisymmetric configuration is an approximation to the square case but is computationally more efficient. It was also found in Ref. 13 that the axisymmetric configuration captures the principal trends displayed in the more accurate square model and therefore is acceptable for approximate trend type studies. It is important to note that the analyses conducted in Ref. 13 were subjected to several simplifying assumptions listed below:

1) Emissivity of the LI-900 tile is unaffected by damage and is constant

2) Conductivities of the tile and SIP are assumed to be functions of only temperature

3) LI-900 tile is assumed to be isotropic

4) Mechanical properties of all materials are constants

The overall objective of this paper is to remove the limitations introduced in Ref. 13 by these simplifying assumptions and improve the previous model so that it is capable of representing the TPS under more realistic conditions. The modified assumptions, which eliminate previous limitations are given below:

1) Emissivity of damaged surface of LI-900 tile is a function of temperature

2) Conductivities of tile and SIP are functions of both temperature and pressure

3) LI-900 tile is transversely isotropic

4) Certain mechanical properties are functions of temperature 
The specific objectives of this paper are:

a. Examine the effect of the simplifying assumptions used previously

b. Examine the effect of damage under realistic conditions and

c. Determine the influence of damage location on the thermal stress of the TPS

These simulations will provide physical insight to facilitate the experimental tests that will be conducted in the near future in our newly developed high temperature structural testing facility.

\section{Modeling and Finite Element Analysis}

\section{A. Finite Element Method}

The finite element simulation is based upon the ABAQUS code version $6.4^{15}$ to obtain the thermomechanical response of the damaged TPS. Thermal-mechanical coupling, which represents the conversion of mechanical energy to thermal energy, is neglected, compared to the much larger amount of energy supplied to the system through thermal loading. The thermomechanical response of the system is obtained in two steps. First, the heat transfer problem is solved to obtain the time-dependent temperature distribution in the TPS due to the applied thermal loads and boundary conditions. Next, the thermal stresses caused by the temperature distributions are determined. The solutions are facilitated by using the same mesh for both the heat transfer and thermal stress problems.

In the previous study, stress singularities were detected at the edges and corners of the material interfaces. The presence of geometric and material discontinuities at these regions gives rise to what is often called the "boundary-layer effect", where stress gradient changes rapidly. Even with considerable refinement, the meshes used had difficulty producing reliable and converged results. Using the most refined meshes obtainable with the meshing software, converged results from locations sufficiently distant from these stress singularities were used. These refined meshes required a very high number of degrees of freedom (dof's), but did not guarantee the accuracy of the solution due to the singular nature of the complex boundary stress field.

Tong and Pian ${ }^{16}$ concluded that refining meshes and increasing order of element formulation when using conventional finite elements, is inadequate for producing convergence in elasticity problems with singularities. Thus, the use of the finest mesh possible may not produce an accurate solution. Wang and Yuan ${ }^{17}$ developed a singular composite-edge element which uses stress intensity factors to characterize singular edge stress field. The results in Ref. 17 indicate that stress results using the singular element start to deviate from results based on the conventional element when one is approaching within 5\% (based on specimen length) of the location of the singularity. Assuming that the boundary layer effects in the TPS are confined to a region of similar proportions, a modified portion of the quarter model of the square configuration that is used in this study with the boundary region shaded in grey is depicted in Figure 5. This boundary region is located at the periphery of the TPS with a width of $5 \%$ of its length near the interface. Since the computational results are based on conventional elements, results in the shaded region are deemed to be unreliable. Thus the meshes used in the study need only to ensure converged results outside this shaded region.

Axisymmetric configurations were used to determine the validity of the simplifying assumptions. The mesh for the $D=1$ " damaged system is shown in Figure 6(a). It consists of 1280 elements with 3963 nodes. The DCAX8 elements are used for the heat transfer analysis and the CAX8 elements for the thermal stress analysis. Both types of elements are eight-noded biquadratic elements, shown in Figure 6(b), available in ABAQUS element library for axisymmetric analyses. The DCAX8 element has one degree of freedom (temperature), while the CAX8 element has two degrees of freedom, displacements $u_{r}$ and $u_{z}$ at each node. The axisymmetric configurations are used because they require fewer computational resources than the square configurations. While the axisymmetric configurations do not represent the square configurations accurately, it was noted that they predict correct trends without excessive computational requirements.

After the effects of the simplifying assumptions are determined, the simplifying assumptions are removed and the analysis for the square configuration is used for the accurate prediction of TPS behavior. The square configuration is also used to determine the effects of damage location, since off-center damage cannot be modeled by the axisymmetric configuration. This effect is examined by displacing the damage from the center of the tile by an offset distance, $\delta=1$ " or 2" as shown in Figure 7.

The square configuration with the damage of size $D=1$ ", displaced from the center by $\delta=1$ " is shown in Figure 8(a). Due to symmetry, the square configuration can be represented by a half model of the TPS. It consists of 112,697 elements with 164,368 nodes. In the square configurations, the DC3D10 and C3D10 
elements are used for the heat transfer and thermal stress problem, respectively. These are ten-noded quadratic tetrahedron elements, shown in Figure 8(b). For the heat transfer problem, the DC3D10 elements have one degree of freedom per node, the temperature at each node, while for the thermal stress problem, the C3D10 element has three degrees of freedom, i.e. the displacements $u_{x}, u_{y}$ and $u_{z}$ at each node.

\section{B. Heat Transfer Analysis}

In the heat transfer analysis, the transient heat flux profile, $q_{\text {ATS }}(t)$ shown in Figure 9, is applied to the top surface of the TPS. This represents the re-entry heat flux profile for the so-called Access to Space (ATS) reference vehicle ${ }^{18}$. The sides and the inner surface of the TPS are assumed to be perfectly insulated, which corresponds to a worst-case scenario.

For the damaged configurations, there is considerable uncertainty regarding the effect of damage on the flow field and thus the heat load experienced by the TPS. To deal with this uncertainty, two thermal loading conditions, $q_{1}(t)$ and $q_{2}(t)$, which represent the lower and upper bounds of the heat load respectively, are applied. On the surface of the damaged region, $S_{d}$ in Figure 10, no heat flux is applied for the lower bound case, while the ATS heat flux profile is applied for the upper bound case, thus:

$$
\begin{array}{lll}
\text { Lower bound: } & q_{1}(t)= \begin{cases}q_{\text {ATS }}(t) & \text { on } \mathrm{S}_{\mathrm{u}} \\
0 & \text { on } \mathrm{S}_{\mathrm{d}}\end{cases} \\
\text { Upper bound: } & q_{2}(t)=q_{\text {ATS }}(t) & \text { on } \mathrm{S}_{\mathrm{u}} \text { and } \mathrm{S}_{\mathrm{d}}
\end{array}
$$

Clearly, on the undamaged surface, $S_{u}$ in Figure 10, the ATS heat flux profile is applied. The primary mechanism of heat loss in the TPS is radiation from the top surface of the tile. Convection heat loss is disregarded. On the undamaged surface, all radiated heat is lost to open space. However, in the damaged region, some of the heat radiated from the damaged surface is intercepted by opposite surfaces, as shown schematically in Figure 11, resulting in lower net heat loss to space. This cavity radiation in the damaged region is accounted for in the analysis by using the keyword commands *CAVITY DEFINITION and *RADIATION VIEWFACTOR in ABAQUS, which determines the heat exchange between element surfaces within the damaged region.

The unsteady heat transfer problem is solved in the time domain by using a carefully selected time-step so as to ensure convergence of the transient solution. This correct time-step is determined by repeatedly solving the heat transfer problem with decreasing time-steps. When the difference in the temperature results between two consecutive time-steps is less than $1.0 \%$, the solution is considered converged.

New nodal temperatures are computed at each time-step based on the time-dependent thermal loading conditions as well as the temperature distribution obtained from the previous time step. The nodal temperatures at each time step are stored for subsequent use by the thermal stress analysis.

\section{Thermal Stress Analysis}

The thermal stress analysis is conducted for two types of boundary conditions, (a) the unrestrained, BC1, and (b) the restrained, BC2 boundary conditions. The schematic description of these boundary conditions is provided in Figure 12. These boundary conditions represent the upper and lower bounds for the possible boundary conditions that may exist in practice. The boundary conditions are applied only to the underlying structure since the tile and SIP are attached to the underlying structure in such a manner that they are not load bearing elements. Symmetric boundary conditions are applied to nodes lying on the axisymmetric line of the axisymmetric configurations and to those lying on the planes of symmetry in the square configurations. The displacements and stresses at each time-step are computed using the timedependent nodal temperatures from the heat transfer solution.

\section{Results and Discussion}

Consider the three-layer LI-900 shuttle tile TPS, where the thickness of the SIP and the underlying structure are 0.173 ” and 0.063 ” respectively. The thickness of the tile is chosen such that the maximum temperature attained by the underlying structure is limited to $150{ }^{\circ} \mathrm{C}$. Thus, depending on whether its conductivity is assumed to be a function of temperature and pressure, or just a function of temperature, the thickness of the tile required for achieving the desired temperature $\left(150{ }^{\circ} \mathrm{C}\right)$ are different. The material 
properties, density $(\rho)$, specific heat $(c)$, thermal conductivity $(k)$, Young's modulus $(E)$, Poisson's ratio $(v)$ and coefficient of thermal expansion ( $\alpha$ ) used in the analyses for the underlying structure (Aluminum) are given in Table 1. The conductivity of the SIP as a function of pressure and temperature are given in Table 2 and its other material properties are shown in Table 3. The conductivity of the LI-900 tile as a function of pressure and temperature can be found in Table 4 . The tile is transversely isotropic and its in-plane ( $x$ zplane) properties are different from the out-of-plane ( $y$-direction) properties. The first value listed is the inplane conductivity while the value in parentheses is the out-of-plane conductivity. Other material properties of the tile are given in Table 5.

\section{A. Validity of assumptions in previous study}

The axisymmetric configuration is used to determine the validity of the simplifying assumptions in the previous study. Starting with the analysis from the previous study, each of the simplifying assumptions mentioned above is replaced with more realistic assumptions one at a time. With each replacement, the results from the previous analysis are compared to the improved one to determine the relative effects of each simplifying assumption. For the results in this section, the $q_{2}$ thermal load and BC2 are used.

1. Emissivity of damaged surfaces as a function of temperature

In the previous study, the emissivity of the tile (0.85) was assumed to be unaffected by damage. In reality, the tile is coated by a reaction cured glass (RCG) that enhances the emissivity characteristics of the tile and limits moisture absorption. Since damage breaches the tile coating, it affects the emissivity. The emissivity of the uncoated tile is a function of temperature (See Table 6) and it decreases with increasing temperature. Assuming that damage totally removes the coating, a new analysis using the axisymmetric, $D$ $=1$ " damage configuration is conducted. The emissivity of the damaged region is now assumed to be temperature-dependent and the emissivity values used correspond to those of an uncoated tile.

The maximum temperatures reached by each TPS component are shown in Table 7 . The rapid decrease in emissivity in the damaged region, coupled with the effect of cavity radiation, severely reduces the radiation heat lost from the surface resulting in very high temperatures in the TPS. From the results, it can be seen that assuming emissivity is unaffected by damage leads to a under-prediction of the maximum temperatures in the system by as much as $31 \%$ and this error is likely to increase with increasing damage size.

2. Conductivity of tile as a function of both temperature and pressure

Previously, the conductivity of the tile and SIP were assumed to be only a function of temperature, i.e. $k=f(T)$ and the conductivity at $P=1013.3$ Pa was used. However, due to the porous nature of the tile, its conductivity is actually a function of both temperature and pressure, i.e. $k=g(T, P)$. During reentry, the static pressure changes from almost zero pressure to atmospheric pressure, which affects the conductivity. To determine how the previous assumption influences the results, a new analysis using the undamaged axisymmetric configuration, with the tile and SIP's conductivities that depend on both temperature and pressure, is performed.

The TPS is assumed to be exposed to a pressure profile shown in Figure 13. There is relatively small increase in pressure in the initial $2400 \mathrm{~s}$, followed by a rapid rise to atmospheric pressure at about $3000 \mathrm{~s}$. Thus, in the previous analysis, the conductivity of the tile used is higher initially, until about $965 \mathrm{~s}$, and becomes lower in the later stage of the analysis.

The thickness of the tile is sized to limit the maximum temperature attained by the underlying structure to $150{ }^{\circ} \mathrm{C}$. With the inclusion of pressure dependency for conductivity in the tile, the required thickness is reduced by about $5 \%$, from 3.09 " to 2.94 ".

Figure 14 depicts the transient temperature results for both the previous and improved analyses at the surface and center of the tile, as well as at the underlying structure. The surface temperature of the tile is largely unaffected by the previous simplifying assumption. However, the temperature distributions within the TPS are significantly modified. The higher initial conductivity used in the previous analysis allowed heat to penetrate faster, resulting in higher temperatures at the center of the tile as seen in the Figure 14(b). In the later times, the reduced conductivity slows the heat penetration to the underlying structure, resulting in a longer duration before the structure reaches its maximum temperature (See Figure 14(c)). The lower conductivity also reduced the heat loss from the TPS by preventing the heat that has penetrated into the TPS earlier from being conducted back to surface of the tile as the surface cools. This aggravates the effects of "temperature soaking", thus a thicker tile is required in the previous analysis. 
The temperature results from the new analysis are used to determine the thermal stress in the TPS. The maximum von Mises stresses that occur in the tile, SIP and underlying structure subjected to BC2 using the previous and new temperature results are shown in Table 8. In neglecting pressure dependency of the conductivity, the von Mises stress in the tile is underestimated by $13.8 \%$. The higher initial conductivity results in less severe thermal gradients, which translate into lower stresses. However, the larger required thickness of the tile results in higher stresses in the SIP and underlying structure.

The assumption that the conductivities of the tile and SIP is only a function of temperature yields conservative results in TPS sizing and the heat transfer analysis, however, it underestimates the maximum stresses in the tile significantly. Thus, it is important to include pressure dependency of conductivity, in order to obtain conservative thermal stress results.

\section{Tile as an transversely isotropic material}

In the previous analysis, the tile was assumed to be isotropic. The tile is actually transversely isotropic, where its out-of-plane properties are different from its in-plane properties. In the heat transfer analysis, only conductivity of the material is affected by this assumption and in the thermal stress analysis, only the elastic material properties are affected. To determine these effects, results from analyses using isotropic and transversely isotropic material properties are compared. In these analyses, improved assumptions from the previous two sections are included.

While trying to incorporate the assumptions of temperature dependency in emissivity, and pressure and temperature dependency in conductivity, some problems with ABAQUS were encountered. To include the temperature dependency in emissivity using ABAQUS requires that the heat transfer analysis be conducted in two stages. An analysis where conductivities of the materials are function of only temperature was conducted as the first stage. The temperature results in the damaged region are stored. In a subsequent analysis, representing the second stage, conductivities of the materials are functions of both temperature and pressure, the temperature results from the first stage are used to govern the selection of emissivity values for the calculations in the second stage. This ensures the correct emissivity data is used. This approximate method yields satisfactory results since the surface temperatures were found to be only marginally affected by the inclusion of pressure dependency in conductivity.

In the previous heat transfer analysis the out-of-plane conductivity was used. From Table 4, it can be seen that the in-plane conductivity used in the previous analysis is about 42 to $55 \%$ lower. Using the transversely isotropic properties with the $D=1$ " axisymmetric configuration, the maximum temperature results were found to be largely unaffected even though temperature distributions in the tile are slightly modified.

The results from the heat transfer analysis described above are used to determine the thermal stress. In the previous analysis, the in-plane stiffness was used for the assumed isotropic properties, thus the out-ofplane stiffness used was about 2.5 times higher. The maximum von Mises stresses that occur in the tile, SIP and underlying structure subjected to BC2 using isotropic and transversely isotropic properties are shown in Table 9. For the $D=1$ " axisymmetric case, the maximum stresses in the TPS are only slightly changed $(<6 \%)$. In the undamaged case, where the heat transfer results between the isotropic and anisotropic tile analyses are the same, the thermal stress results show a much larger difference in the tile (14.2\%).

Assuming an isotropic tile was found to influence the results in most cases and the changes are not all conservative. It should also be noted that von Mises stress is not used as a failure criterion for anisotropic materials. Generally, for these materials, the Hill criterion ${ }^{19}$ is applied.

\section{Temperature dependent mechanical properties}

The coefficient of thermal expansion (CTE) for the tile, and the CTE and Young's modulus of the underlying structure are actually functions of temperature. For the underlying structure, the CTE increases with temperature while the modulus decreases. The CTE of the LI-900 tile does not increase monotonically with temperature; instead it increases with temperatures up to about $540{ }^{\circ} \mathrm{C}$, after which it decreases. In Ref. 13, all mechanical properties are assumed to be constants. The room temperature CTE and modulus were used for the underlying structure. For the tile, an "average" value of CTE $\left(6.06 \times 10^{-7} /{ }^{\circ} \mathrm{C}\right)$ was used.

The maximum von Mises stresses that occur in the tile, SIP and underlying structure for the undamaged and $D=1$ ” axisymmetric configurations subjected to BC2 for constant and temperature dependent mechanical properties are shown in Table 10. For the undamaged configuration, using constant mechanical properties produces lower maximum von Mises stresses in the tile and underlying structure, however, for the damaged configuration, these stresses are higher.

In the structure, the decrease in stiffness produces a decrease in maximum stresses, but this is overcome by the increase in stress due to the increase in CTE. Thus higher stresses are obtained in the analyses where 
mechanical properties are functions of temperature. For the damaged configuration, where the temperature reached in the structure is higher, the effects of the decreasing modulus outweigh that of the increasing CTE, so lower stresses are obtained. However, these differences are modest $(<10 \%)$.

For the tile, the different CTE used (see Figure 15) gives rise to interesting results. For the undamaged configuration, the maximum von Misses stress using constant mechanical properties is lower by about $3 \%$ while the stress is higher by about $80 \%$ for the damaged configuration. The maximum temperature reached in the undamaged configuration is relatively low, at about $980{ }^{\circ} \mathrm{C}$. The maximum stress for the analysis based on constant mechanical properties is reached when the maximum temperature occurs. This is not true for the case with temperature dependent properties. In this case, the maximum stress was reached when the maximum temperature in the tile was at about $540{ }^{\circ} \mathrm{C}$, which corresponds to the temperature where CTE is the highest. In the damaged configuration, however, the maximum temperature in the tile is so high that the maximum stresses occur when the maximum temperature is reached, even with the reduction in CTE at these high temperatures. The high maximum temperatures also produces a large over-prediction in maximum stresses when the "average" constant CTE is used.

\section{Thermomechanical behavior with improved assumptions}

Analyses for the square configurations with the improved assumptions were conducted to obtain a more realistic behavior of the TPS and the results of these computations are described next.

1. Comparison with previous results

The maximum temperatures that occur in the tile, SIP and underlying structure, including the times when they occur are shown in Tables 11 and 12 respectively. These results are for the earlier simplified models as well as for the more refined models for both the baseline and damaged configurations. Two values are provided for each damaged configuration: one for the $q_{1}$ thermal loading case (left column) and the other for the $q_{2}$ thermal loading case (right column). The percentage change in the maximum temperatures for the damaged configurations compared to the undamaged (baseline) configuration are also provided in the tables.

The lower bound temperatures for all TPS components are relatively insensitive to the changes in the assumptions. For the upper bound temperatures, the reduction in emissivity in the damage raises the temperatures significantly. The effects of damage size on these temperatures are also more severe with the new assumptions. Maximum temperatures in the SIP and underlying structure also occur at earlier times. Tables 13 to 15 provide the maximum von Mises stress in the tile, SIP and underlying structure, and the times at which they occur for both thermal loading cases from Ref. 13, while Tables 16 to 18 present the same information using the new assumptions. In the tables, two maximum stresses, one for the unrestrained boundary condition, BC1, and one for the restrained boundary condition, BC2, are provided. The percentage changes in these stresses in the damaged configurations, with respect to the baseline configuration, are also indicated.

For the lower bound loading case, the maximum stresses in the tile are quite similar. The maximum difference between the two sets of results at approximate $-5.5 \%$. For the upper bound loading case, the differences are larger. The higher temperatures in the tile as a result of the new assumptions did not produce higher maximum stresses. The maximum stresses are actually lower due to the lower CTE used. The differences in the results are between $13 \%$ and $44 \%$.

In the SIP, maximum stresses using the new assumptions are higher in the BC1 cases while that for the BC2 cases are generally lower. The differences in results vary between $-51 \%$ and $50 \%$. These differences are due to a combination of higher temperatures and the larger CTE mismatch between the tile and the underlying structure.

With the new assumptions, the maximum stresses in the underlying structure for the BC1 cases are generally lower while those for the BC2 cases are all higher. Differences in this set of results are between $36 \%$ and $26 \%$. The higher temperatures and the changing CTE and stiffness of the underlying structure with respect to temperature are the primary cause of the differences.

It is evident that the simplifying assumptions used in the previous analyses have produced results that have substantial errors. It is not possible to choose simplifying assumptions that guarantee conservative results. Therefore, it is important to use the more refined models that incorporate realistic assumptions.

2. Effects of Damage on TPS

The lower bound maximum temperatures in the tile occur outside the damaged area and thus are unaffected by damage. For the tile, with $q_{2}$ loading, the smallest damage considered raises the maximum temperature in the tile by $88.2 \%$ to above the melting point of the tile material $\left(1704{ }^{\circ} \mathrm{C}\right)$. Increasing the 
damage size to $D=1.5$ " increases the maximum temperature by $117.4 \%$. The large temperature increases is due to the fact that the upper bound thermal loading condition is likely to be more severe than actual conditions. However, these results suggest that damage has the potential for raising the temperatures in the tile to above its melting point.

The lower bound temperatures in the SIP and underlying structure were found to decrease modestly with increasing damage. For the upper bound temperatures, increases in temperature is much more severe, up to $154.7 \%$ for the $D=1.5$ " damage. This increase is even higher than what is obtained for the tile layer.

It should be emphasized that the thermal stress results are obtained while disregarding the fact that the melting temperature of the tile has been exceeded. For the tile, even for the lower bound loading where temperatures in the damaged cases are similar to those in the undamaged one, stresses were found to increase with damage. The increase in stresses decreases with damage size, suggesting that the increase is the result of stress concentration due to the damage. This is because the severity of stress concentration decreases with increasing damage size. For the upper bound loading cases, the stresses are found to increase with increasing damage size. For the $D=1.5$ ”, the stress was found to increase by $103.7 \%$.; due primarily to the large increase in temperatures.

In the SIP and structure, stresses due to the lower bound loading were found to decrease with increasing damage size and vice versa for the upper bound loading condition. For these two layers, the change in maximum stresses seems to be directly related to changes in the maximum temperature results, because the changes in stress with respect to damage size are similar to the changes in temperature. Only in two cases were the stresses above the failure strength of the material. These are obtained in the structure for the $q_{2}$ loading, BC2 cases with $D=1$ ” and 1.5”. However, it should be noted that no heat lost through the inner surface of the structure was assumed, a conservative assumption.

\section{E. Effects of damage location}

Using the $D=1$ " square configuration with $q_{2}$ thermal loading, the maximum temperatures reached in each TPS component for each value of $\delta$, representing different damage locations are provided in Table 19. The maximum temperature in the tile increase by only $4.4 \%$ with increasing damage offset distance from the center. This is probably due to the insulated boundary condition on the side of the TPS. The maximum temperatures in the SIP and structure were found to remain almost unchanged. Thus, for the cases considered here, the results indicate that the maximum temperatures in the TPS remain practically unchanged.

The maximum von Mises stresses that occur in the tile, SIP and underlying structure are shown in Table 20. In the BC1 case, the stress in the tile was found to decrease by up to $5.9 \%$ when damage was displaced from the center. In the BC2 case, the stress in the tile was found to decrease by up to $21.3 \%$. For the SIP and underlying structure, the changes in stresses are very small $(<3.5 \%)$.

From these results, it can be seen that damage location has only a minor effect in the SIP and underlying structure, but it is more significant on the tile. However, results for $\delta=0$ " are the most severe. Since central damage appears to be the worst-case scenario with respect to damage location, in future work, only this type of damage will be considered for future studies.

\section{Concluding Remarks}

The simplifying assumptions used in the previous paper limit the accuracy of the analyses. The effects of these assumptions are examined in detail by comparing the results with those using more realistic assumptions. For the cases considered, which include three very dissimilar materials operating under a wide range of temperature and pressure, these simplifying assumptions were found to affect the accuracy of the results in a fairly complicated manner, from which it cannot be concluded that the simplifying assumptions are conservative. Thus, it is not recommended using these simplifying assumptions. Instead reliable results for reusable TPS should be based on realistic material properties and loading conditions.

The thermomechanical analyses of the system obtained with the refined assumptions produce a substantial number of important results. These results indicate that the presence of damage is capable of increasing the maximum temperature in the tile to its melting point and may result in structural damage in the underlying structure.

The influence of damage location on the thermal stress results was also examined. The damage location influences primarily the tile and damage at the center of the tile produced the highest maximum stresses. 
Therefore, it was concluded that this represents the worst-case scenario. This justifies considering the centrally located damage exclusively in future studies.

The TPS is a critical component of space transport systems and failure can have catastrophic consequences. Thus, understanding the effects of damage on the TPS is of fundamental importance. The results presented provide valuable insight to the damage tolerance of TPS and can eventually be used in the development of more damage tolerant TPS.

\section{Acknowledgments}

This work was supported by the Space Vehicle Technology Institute under grant NCC3-989 jointly funded by NASA and DOD within the NASA Constellation University Institutes Project, with Claudia Meyer as the project manager.

\section{References}

1 Scotti, S.J., Clay, C. and Rezin, M., "Structures and Materials Technologies for Extreme Environments Applied to Reusable Launch Vehicles". AIAA/ICAS International Symposium and Exposition, AIAA Paper 2003-2697, Dayton, OH, Jul. 2003.

2 Ko, W.L. and Jenkins, J.M., "Thermal Stress Analysis of Space Shuttle Orbiter Wing Skin Panel and Thermal Protection System”, NASA Technical Memorandum 88276.

3 Sawyer, J.W., "Effect of Strain Isolator Pad on Inplane Strain in Shuttle Orbiter Thermal Protection System Tiles”, NASA Technical Paper 2141.

4 Moser, T.L. and Schineider, W.C., "Strength Integrity of the Space Shuttle Orbiter Tiles", AIAA-812469, $1^{\text {st }}$ Flight Testing Conference, Las Vegas, NV, NOV. 1981.

5 Cooper, P.A., Miserentino, R., Sawyer, J.W. and Leatherwood, J.D., "Effect of Simulated Mission Loads on Orbiter Thermal Protection System Undensified Tiles", Journal of Spacecraft and Rockets, Vol. 21, No. 5. Sep-Oct 1984

6 Ried, T.C., Goodrich, W.D., Li, C.P., Scott, C.D., Derry, S.M. and Maraia, R.J., “Space Shuttle Orbiter Entry Heating and TPS Response: STS-1 Predictions and Flight Data", NASA Conference Publication 2216, Pg. 327-347, 1982

7 Dotts, R.L., Smith, J.A. and Tillian, D.J., "Space Shuttle Orbiter Reusable Surface Insulation Flight Results”, NASA Conference Publication 2283, Part 2, Pg. 949-966, 1983.

8 Neuenschwander, W.E., McBride, D.U. and Armour, G.A., "Shuttle TPS Thermal Performance and Analysis Methodology”, NASA Conference Publication 2283, Part 2, Pg. 1025-1064, 1983.

9 Shideler, J.L., Kelly, H.N., Avery, D.E., Blosser, M.L. and Adelman, H.M., "Multiwall TPS - An Emerging Concept”, Journal of Spacecraft and Rockets, Vol. 19, No. 4, Jul-Aug 1982.

10 Frank S. Milos and Thomas H. Squire, "Thermostructural Analysis of X-34 Wing Leading-Edge Tile Thermal Protection System”, Journal of Spacecraft and Rockets, Vol. 36, No. 2, Mar-Apr 1999.

11 Shideler, J.L., Webb, G.L. and Pittman, C.M., "Verification Tests of Durable Thermal Protection System Concepts”, Journal of Spacecraft and Rockets, Vol. 22, No. 6, Nov-Dec 1985.

12 Blosser, M.L., Chen, R.R., Schmidt, I.H., Dorsey, J.T., Poteet, C.C. and Bird, R.K., "Advanced Metallic Thermal Protection System Development”, AIAA $40^{\text {th }}$ Aerospace Sciences Meeting \& Exhibit, AIAA Paper 2002-0504, Reno, NV, Jan. 2002

13 Ng, W.H., Friedmann, P.P, Waas, A.M., "Thermomechanical Analysis of a Damaged Thermal Protection System", AIAA Paper No. 2005-2301, 46 ${ }^{\text {th }}$ AIAA/ASME/ASCE/AHS/ASC Structures, Structural Dynamics, and Materials Conference, Austin TX, Apr 2005

14 Christiansen, E.L. and Friesen, L., "Penetration Equations for Thermal Protection Material", International Journal Impact Engineering, Vol. 20, Pg. 153-164, 1997

15 “ABAQUS/Standard User's Manual Version 6.4,” Hibbitt, Karlsson \& Sorensen, Inc., Pawtucket, RI.

16 Tong, P., and Pian, T.H.H., "On Convergence of the Finite Element Methods for Problems with Singularity,” International Journal of Solids and Structures, Vol. 9, Pg. 313-321, 1973

17 Wang, S.S., and Yuan, F.K., "A Singular Hybrid Finite Element Analysis of Boundary-Layer Stresses in Composite Laminates," International Journal of Solids and Structures, Vol. 19, No. 9 Pg. 825-837, 1983

18 Myers, D.E., Martin, C.J. and Blosser, M.L., "Parametric Weight Comparison of Advanced Metallic, 
Ceramic Tile, and Ceramic Blanket Thermal Protection Systems,” NASA TM-2000-210289, June 2000

19 Hill, R., “A Theory of the Yielding and Plastic Flow of Anisotropic Metals," Proceedings of the Royal Society of London, Series A, Mathematical and Physical Sciences, Vol. 193, No. 1033, Pg. 281-197, May 1948. 


\begin{tabular}{||c||c||c||c||c||}
\hline $\begin{array}{c}\mathbf{T} \\
\left({ }^{\circ} \mathbf{C}\right)\end{array}$ & $\begin{array}{c}\mathbf{C} \\
\left(\mathbf{J} / \mathbf{k g}^{\circ} \mathbf{C}\right)\end{array}$ & $\begin{array}{c}\mathbf{k} \\
\left(\mathbf{W} / \mathbf{m}^{\circ} \mathbf{C}\right)\end{array}$ & $\begin{array}{c}\mathbf{E} \\
(\mathbf{G P a})\end{array}$ & $\begin{array}{c}\boldsymbol{\alpha} \\
\left(\mathbf{1 0} \mathbf{6}^{-} /{ }^{\circ} \mathbf{C}\right)\end{array}$ \\
\hline \hline-73.2 & 787.0 & 163.0 & - & - \\
\hline-17.8 & - & - & - & 21.9 \\
\hline 21.0 & - & - & 72.4 & - \\
\hline 26.9 & 875.0 & 177.0 & - & - \\
\hline 37.8 & - & - & 72.0 & 22.6 \\
\hline 93.3 & - & - & 70.4 & 23.2 \\
\hline 126.9 & 925.0 & 186.0 & - & - \\
\hline 148.9 & - & - & 68.5 & 23.6 \\
\hline 204.4 & - & - & 64.3 & 24.0 \\
\hline 260.0 & - & - & 57.3 & 24.4 \\
\hline 315.6 & - & - & 50.5 & 24.9 \\
\hline 326.9 & 1042.0 & - & - & - \\
\hline 371.1 & - & - & - & 25.4 \\
\hline 426.7 & - & - & - & 26.0 \\
\hline 482.2 & - & - & - & 26.7 \\
\hline
\end{tabular}

$\rho=2770 \mathrm{~kg} / \mathrm{m}^{3}$

$v=0.33$

Table 1. Material properties of the underlying structure (Aluminum 2024)

\begin{tabular}{|c|c|c|c|c|c|}
\hline \multirow[b]{2}{*}{$\mathrm{T}\left({ }^{\circ} \mathrm{C}\right)$} & \multicolumn{5}{|c|}{$\mathbf{P}(\mathbf{P a})$} \\
\hline & 10.133 & 101.33 & 1013.3 & 10133 & 101330 \\
\hline-17.6 & 0.009173 & 0.01904 & 0.03081 & 0.03427 & 0.03548 \\
\hline 38.0 & 0.009865 & 0.02146 & 0.03600 & 0.04067 & 0.04223 \\
\hline 93.5 & 0.01090 & 0.02337 & 0.04154 & 0.04725 & 0.04933 \\
\hline 149.1 & 0.01263 & 0.02631 & 0.04708 & 0.05504 & 0.05711 \\
\hline 204.6 & 0.01575 & 0.02908 & 0.05244 & 0.06421 & 0.06611 \\
\hline 315.7 & 0.02077 & 0.03548 & 0.06750 & 0.08308 & 0.08533 \\
\hline 426.9 & 0.02700 & 0.04327 & 0.08654 & 0.1052 & 0.1073 \\
\hline
\end{tabular}

Table 2. Conductivity of SIP $\left(\mathrm{W} / \mathrm{m}^{-}{ }^{\circ} \mathrm{C}\right)$ with respect to temperature and pressure

\begin{tabular}{|c||c||}
\hline $\begin{array}{c}\mathbf{T} \\
\left({ }^{\circ} \mathbf{C}\right)\end{array}$ & $\begin{array}{c}\mathbf{C} \\
\left(\mathbf{J} / \mathbf{k g}^{\circ} \mathbf{C}\right)\end{array}$ \\
\hline \hline-17.6 & 1306.3 \\
\hline 93.5 & 1339.8 \\
\hline 204.6 & 1402.6 \\
\hline 615.7 & 1444.5 \\
\hline
\end{tabular}

$$
\begin{aligned}
& \rho=194 \mathrm{~kg} / \mathrm{m}^{3} \\
& \mathrm{E}=807 \mathrm{kPa} \\
& v=0.3 \\
& \alpha=18 \times 10^{-6} /{ }^{\circ} \mathrm{C}
\end{aligned}
$$

Table 3. Material properties of SIP 


\begin{tabular}{|c|c|c|c|c|c|}
\hline \multirow[b]{2}{*}{$\mathrm{T}\left({ }^{\circ} \mathrm{C}\right)$} & \multicolumn{5}{|c|}{$\mathbf{P}$ (Pa) } \\
\hline & 10.133 & 101.33 & 1013.3 & 10133 & 101330 \\
\hline-17.6 & $\begin{array}{c}0.02597 \\
(0.01298) \\
\end{array}$ & $\begin{array}{c}0.03116 \\
(0.01731) \\
\end{array}$ & $\begin{array}{c}0.04847 \\
(0.03168) \\
\end{array}$ & $\begin{array}{c}0.05712 \\
(0.04328) \\
\end{array}$ & $\begin{array}{c}0.06751 \\
(0.04760) \\
\end{array}$ \\
\hline 121.3 & $\begin{array}{c}0.03462 \\
(0.01593)\end{array}$ & $\begin{array}{c}0.03981 \\
(0.02164)\end{array}$ & $\begin{array}{c}0.05712 \\
(0.03895)\end{array}$ & $\begin{array}{c}0.07097 \\
(0.05470)\end{array}$ & $\begin{array}{c}0.08136 \\
(0.05903)\end{array}$ \\
\hline 260.2 & $\begin{array}{c}0.04501 \\
(0.02164)\end{array}$ & $\begin{array}{c}0.05193 \\
(0.02891) \\
\end{array}$ & $\begin{array}{c}0.07270 \\
(0.04778)\end{array}$ & $\begin{array}{c}0.08828 \\
(0.06924)\end{array}$ & $\begin{array}{c}0.09867 \\
(0.07495)\end{array}$ \\
\hline 399.1 & $\begin{array}{c}0.06059 \\
(0.03029)\end{array}$ & $\begin{array}{c}0.06924 \\
(0.3739)\end{array}$ & $\begin{array}{c}0.08828 \\
(0.05626)\end{array}$ & $\begin{array}{c}0.1108 \\
(0.08517)\end{array}$ & $\begin{array}{c}0.1212 \\
(0.09244)\end{array}$ \\
\hline 538.0 & $\begin{array}{c}0.08482 \\
(0.04033)\end{array}$ & $\begin{array}{c}0.09001 \\
(0.04760)\end{array}$ & $\begin{array}{c}0.1091 \\
(0.06786)\end{array}$ & $\begin{array}{c}0.1402 \\
(0.1039)\end{array}$ & $\begin{array}{c}0.1523 \\
(0.1139)\end{array}$ \\
\hline 676.9 & $\begin{array}{c}0.1142 \\
(0.05331)\end{array}$ & $\begin{array}{c}0.1229 \\
(0.06059) \\
\end{array}$ & $\begin{array}{c}0.1437 \\
(0.08517) \\
\end{array}$ & $\begin{array}{c}0.1800 \\
(0.1255) \\
\end{array}$ & $\begin{array}{c}0.1921 \\
(0.1354) \\
\end{array}$ \\
\hline 815.7 & $\begin{array}{c}0.1541 \\
(0.07201)\end{array}$ & $\begin{array}{c}0.1662 \\
(0.07945) \\
\end{array}$ & $\begin{array}{c}0.1887 \\
(0.1068) \\
\end{array}$ & $\begin{array}{c}0.2285 \\
(0.1515)\end{array}$ & $\begin{array}{c}0.2423 \\
(0.1631)\end{array}$ \\
\hline 954.6 & $\begin{array}{c}0.2060 \\
(0.09815) \\
\end{array}$ & $\begin{array}{c}0.2164 \\
(0.1056) \\
\end{array}$ & $\begin{array}{c}0.2423 \\
(0.1328) \\
\end{array}$ & $\begin{array}{c}0.2891 \\
(0.1835) \\
\end{array}$ & $\begin{array}{c}0.3029 \\
(0.1956) \\
\end{array}$ \\
\hline 1093.5 & $\begin{array}{c}0.2648 \\
(0.1271) \\
\end{array}$ & $\begin{array}{c}0.2804 \\
(0.1354)\end{array}$ & $\begin{array}{c}0.3116 \\
(0.1631)\end{array}$ & $\begin{array}{c}0.3670 \\
(0.2198)\end{array}$ & $\begin{array}{c}0.3826 \\
(0.2354)\end{array}$ \\
\hline 1260.2 & $\begin{array}{c}0.3687 \\
(0.1672)\end{array}$ & $\begin{array}{c}0.3826 \\
(0.1766)\end{array}$ & $\begin{array}{c}0.4154 \\
(0.2008)\end{array}$ & $\begin{array}{c}0.4726 \\
(0.2683)\end{array}$ & $\begin{array}{c}0.4985 \\
(0.2891)\end{array}$ \\
\hline 1371.3 & $\begin{array}{c}- \\
(0.2008)\end{array}$ & $\begin{array}{c}- \\
(0.2129)\end{array}$ & $\begin{array}{c}- \\
(0.2406)\end{array}$ & $\begin{array}{c}- \\
(0.3098)\end{array}$ & $\begin{array}{c}- \\
(0.3358) \\
\end{array}$ \\
\hline 1538.0 & $\begin{array}{c}- \\
(0.2666)\end{array}$ & $\begin{array}{c}- \\
(0.2804)\end{array}$ & $\begin{array}{c}- \\
(0.3116)\end{array}$ & $\begin{array}{c}- \\
(0.3843)\end{array}$ & $\begin{array}{c}- \\
(0.4189)\end{array}$ \\
\hline 1649.1 & $\begin{array}{c}- \\
(0.3289)\end{array}$ & $\begin{array}{c}- \\
(0.3393)\end{array}$ & $\begin{array}{c}- \\
(0.3791)\end{array}$ & $\begin{array}{c}- \\
(0.4535)\end{array}$ & $\begin{array}{c}- \\
(0.5020)\end{array}$ \\
\hline
\end{tabular}

Table 4. Conductivity of LI-900 tile $\left(\mathrm{W} / \mathrm{m}-{ }^{\circ} \mathrm{C}\right)$ with respect to temperature and pressure

\begin{tabular}{||c||c||c||}
\hline $\begin{array}{c}\mathbf{T} \\
\left({ }^{\circ} \mathbf{C}\right)\end{array}$ & $\begin{array}{c}\mathbf{C} \\
\left(\mathbf{J} / \mathbf{k g}^{\circ} \mathbf{C}\right)\end{array}$ & $\begin{array}{c}\boldsymbol{\alpha} \\
\left(\mathbf{1 0}^{-6} /{ }^{\circ} \mathbf{C}\right)\end{array}$ \\
\hline \hline-17.6 & 628.0 & 0.405 \\
\hline 121.3 & 879.2 & 0.540 \\
\hline 260.2 & 1055.1 & 0.648 \\
\hline 399.1 & 1151.4 & 0.720 \\
\hline 538.0 & 1205.8 & 0.792 \\
\hline 676.9 & 1239.3 & 0.576 \\
\hline 815.7 & 1256.0 & 0.480 \\
\hline 926.9 & 1264.4 & 0.432 \\
\hline 954.6 & 1268.6 & - \\
\hline 1093.5 & - & 0.360 \\
\hline
\end{tabular}

$\begin{array}{llll}\rho & = & 194 & \mathrm{~kg} / \mathrm{m}^{3} \\ \mathrm{E}_{\mathrm{x}}, \mathrm{E}_{\mathrm{z}} & = & 172.4 & \mathrm{MPa} \\ \mathrm{E}_{\mathrm{y}} & = & 48.3 & \mathrm{MPa} \\ \mathrm{G}_{\mathrm{xy}}, \mathrm{G}_{\mathrm{yz}} & =20.7 & \mathrm{MPa} \\ \mathrm{G}_{\mathrm{xz}} & =72.4 & \mathrm{MPa} \\ v_{\mathrm{xy}} & =0.16 & \\ v_{\mathrm{xz}} & =0.18 & \\ v_{\mathrm{yz}} & =0.04 & \end{array}$

Table 5. Material properties of LI-900 tiles 


\begin{tabular}{||c|c||}
\hline Temperature $\left({ }^{\circ} \mathbf{C}\right)$ & Emissivity of Uncoated LI-900 Tile \\
\hline 27 & 0.88050 \\
\hline 127 & 0.83613 \\
\hline 227 & 0.76578 \\
\hline 327 & 0.68410 \\
\hline 427 & 0.60390 \\
\hline 527 & 0.53177 \\
\hline 627 & 0.46981 \\
\hline 727 & 0.41785 \\
\hline 827 & 0.37477 \\
\hline 927 & 0.33918 \\
\hline 1027 & 0.30980 \\
\hline 1127 & 0.28548 \\
\hline 1227 & 0.26527 \\
\hline 1327 & 0.24841 \\
\hline
\end{tabular}

Table 6. Emissivity of uncoated tile with respect to temperature

\begin{tabular}{||c|c|c||}
\hline $\begin{array}{c}\text { TPS } \\
\text { Component }\end{array}$ & $\begin{array}{c}\text { Max. temperatures with constant } \\
\text { emissivity } \\
\left({ }^{\circ} \mathbf{C}\right)\end{array}$ & $\begin{array}{c}\text { Max. temperature with emissivity as } \\
\text { function of temperature } \\
\left({ }^{\circ} \mathbf{C}\right)\end{array}$ \\
\hline LI-900 & 1501 & 2178 \\
\hline SIP & 188.1 & 228.9 \\
\hline Structure & 187.3 & 228.1 \\
\hline
\end{tabular}

Table 7. Maximum temperature results for $D=1$ " axisymmetric configuration for analyses with or without temperature dependent emissivity

\begin{tabular}{||c|c|c||}
\hline TPS & $\begin{array}{c}\text { Max. von Mises stress with } \\
\boldsymbol{k}=\boldsymbol{f}(\mathbf{T}) \quad(\mathbf{P a})\end{array}$ & $\begin{array}{c}\text { Max. von Mises stress with } \\
\boldsymbol{k}=\boldsymbol{g}(\boldsymbol{T}, \boldsymbol{P}) \quad(\mathbf{P a})\end{array}$ \\
\hline Component & $6.20 \times 10^{4}$ & $7.17 \times 10^{4}$ \\
\hline LI-900 & $4.03 \times 10^{3}$ & $2.86 \times 10^{3}$ \\
\hline SIP & $2.81 \times 10^{8}$ & $2.80 \times 10^{8}$ \\
\hline Structure & & \\
\hline
\end{tabular}

Table 8. Maximum von Mises stresses attained for each TPS component for analyses with or without pressure dependency in conductivity

\begin{tabular}{|c|c|c|c|}
\hline$D$ & $\begin{array}{c}\text { TPS } \\
\text { Component }\end{array}$ & $\begin{array}{l}\text { Max. von Mises stress with } \\
\text { isotropic properties } \\
\text { (Pa) }\end{array}$ & $\begin{array}{c}\text { Max. von Mises stress with } \\
\text { transversely isotropic properties } \\
(\mathrm{Pa})\end{array}$ \\
\hline \multirow{3}{*}{ 0” } & LI-900 & $7.17 \times 10^{4}$ & $6.15 \times 10^{4}$ \\
\hline & SIP & $2.86 \times 10^{3}$ & $2.83 \times 10^{3}$ \\
\hline & Structure & $2.80 \times 10^{8}$ & $2.79 \times 10^{8}$ \\
\hline \multirow{3}{*}{ 1” } & LI-900 & $2.11 \times 10^{5}$ & $2.09 \times 10^{5}$ \\
\hline & SIP & $5.15 \times 10^{3}$ & $5.41 \times 10^{3}$ \\
\hline & Structure & $5.04 \times 10^{8}$ & $5.34 \times 10^{8}$ \\
\hline
\end{tabular}

Table 9. Maximum von Mises stresses attained for each TPS component for the analysis using isotropic and transversely isotropic material properties 


\begin{tabular}{|c||c||c|c||}
\hline \multirow{2}{*}{$\boldsymbol{D}$} & $\begin{array}{c}\text { TPS } \\
\text { Component }\end{array}$ & $\begin{array}{c}\text { Max. von Mises stress with } \\
\text { constant mechanical properties } \\
(\mathbf{P a})\end{array}$ & $\begin{array}{c}\text { Max. von Mises stress with } \\
\text { mechanical properties as } \\
\text { function of temperature (Pa) }\end{array}$ \\
\hline \hline \multirow{3}{*}{ 0" } & LI-900 & $6.15 \times 10^{4}$ & $6.34 \times 10^{4}$ \\
\cline { 2 - 4 } & SIP & $2.83 \times 10^{3}$ & $2.83 \times 10^{3}$ \\
\cline { 2 - 4 } & Structure & $2.79 \times 10^{8}$ & $3.09 \times 10^{8}$ \\
\hline \multirow{3}{*}{ 1" } & LI-900 & $2.09 \times 10^{5}$ & $1.16 \times 10^{5}$ \\
\cline { 2 - 4 } & SIP & $5.41 \times 10^{3}$ & $5.46 \times 10^{3}$ \\
\cline { 2 - 4 } & Structure & $5.34 \times 10^{8}$ & $5.05 \times 10^{8}$ \\
\hline
\end{tabular}

Table 10. Maximum von Mises stresses attained for each TPS component for the analyses with constant and temperature-dependent mechanical properties

\begin{tabular}{|c|c|c|c|c|c|c|c|}
\hline $\begin{array}{c}\text { TPS } \\
\text { component }\end{array}$ & $\begin{array}{c}D \\
\text { (inch) }\end{array}$ & \multicolumn{2}{|c|}{$\begin{array}{c}\text { Temperature } \\
\left({ }^{\circ} \mathrm{C}\right) \\
\end{array}$} & \multicolumn{2}{|c|}{$\%$ change } & \multicolumn{2}{|c|}{$\begin{array}{c}\text { Time } \\
\text { (s) }\end{array}$} \\
\hline \multirow{4}{*}{ Tile } & 0 & \multicolumn{2}{|c|}{981} & \multicolumn{2}{|c|}{ NA } & \multicolumn{2}{|c|}{850} \\
\hline & 0.5 & 981 & 1457 & 0 & 48.5 & 850 & 850 \\
\hline & 1.0 & 981 & 1499 & 0 & 52.8 & 850 & 850 \\
\hline & 1.5 & 981 & 1515 & 0 & 54.4 & 850 & 850 \\
\hline \multirow{4}{*}{ SIP } & 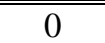 & \multicolumn{2}{|c|}{150} & \multicolumn{2}{|c|}{ NA } & \multicolumn{2}{|c|}{66600} \\
\hline & 0.5 & 149 & 156 & -0.7 & 4.0 & 6550 & 6550 \\
\hline & 1.0 & 145 & 180 & -3.3 & 20.0 & 6450 & 6300 \\
\hline & 1.5 & 139 & 225 & -7.3 & 50.0 & 6250 & 5800 \\
\hline \multirow{4}{*}{$\begin{array}{l}\text { Underlying } \\
\text { structure }\end{array}$} & 0 & \multicolumn{2}{|c|}{150} & \multicolumn{2}{|c|}{ NA } & \multicolumn{2}{|c|}{7150} \\
\hline & 0.5 & 148 & 156 & -1.3 & 4.0 & 7150 & 7100 \\
\hline & 1.0 & 144 & 179 & -4.0 & 19.3 & 7100 & 6850 \\
\hline & 1.5 & 138 & 224 & -8.0 & 49.3 & 6900 & 6300 \\
\hline
\end{tabular}

Table 11. Maximum temperatures results for square configurations from Ref. 13

\begin{tabular}{|c|c|c|c|c|c|c|c|}
\hline $\begin{array}{c}\text { TPS } \\
\text { component }\end{array}$ & $\begin{array}{c}D \\
\text { (inch) }\end{array}$ & \multicolumn{2}{|c|}{$\begin{array}{c}\text { Temperature } \\
\left({ }^{\circ} \mathrm{C}\right)\end{array}$} & \multicolumn{2}{|c|}{$\%$ change } & \multicolumn{2}{|c|}{$\begin{array}{c}\text { Time } \\
\text { (s) }\end{array}$} \\
\hline \multirow{4}{*}{ Tile } & 0 & \multicolumn{2}{|c|}{981} & \multicolumn{2}{|c|}{ NA } & \multicolumn{2}{|c|}{850} \\
\hline & 0.5 & 981 & 1846 & 0 & 88.2 & 850 & 850 \\
\hline & 1.0 & 981 & 2048 & 0 & 108.8 & 850 & 850 \\
\hline & 1.5 & 981 & 2133 & 0 & 117.4 & 850 & 850 \\
\hline \multirow{4}{*}{ SIP } & 0 & \multicolumn{2}{|c|}{150} & \multicolumn{2}{|c|}{ NA } & \multicolumn{2}{|c|}{5000} \\
\hline & 0.5 & 148 & 167 & -1.3 & 11.3 & 5000 & 4900 \\
\hline & 1.0 & 145 & 242 & -3.3 & 61.3 & 4900 & 4550 \\
\hline & 1.5 & 140 & 382 & -6.7 & 154.7 & 4750 & 3900 \\
\hline \multirow{4}{*}{$\begin{array}{l}\text { Underlying } \\
\text { structure }\end{array}$} & 0 & \multicolumn{2}{|c|}{10150} & \multicolumn{2}{|c|}{ NA } & \multicolumn{2}{|c|}{5450} \\
\hline & 0.5 & 148 & 166 & -1.3 & 10.7 & 5450 & 5350 \\
\hline & 1.0 & 144 & 241 & -4.0 & 60.7 & 5400 & 4950 \\
\hline & 1.5 & 139 & 380 & -7.3 & 153.3 & 5300 & 4200 \\
\hline
\end{tabular}

Table 12. Maximum temperatures results for square configurations using new assumptions 


\begin{tabular}{|c|c|c|c|c|c|c|c|}
\hline \multirow{2}{*}{$\begin{array}{l}\text { Thermal } \\
\text { Loading }\end{array}$} & \multirow[t]{2}{*}{$\begin{array}{c}D \\
\text { (inch) }\end{array}$} & \multicolumn{2}{|c|}{$\begin{array}{c}\text { Max. von Mises stress } \\
\text { (kPa) }\end{array}$} & \multicolumn{2}{|c|}{$\%$ change } & \multicolumn{2}{|c|}{$\begin{array}{l}\text { Time } \\
\text { (s) }\end{array}$} \\
\hline & & BC1 & BC2 & BC1 & BC2 & BC1 & BC2 \\
\hline \multirow{4}{*}{$q_{1}$} & 0 & 63.4 & 63.6 & NA & NA & 350 & 350 \\
\hline & 0.5 & 111.2 & 111.6 & 75.4 & 75.5 & 350 & 350 \\
\hline & 1.0 & 99.5 & 99.9 & 56.9 & 57.1 & 400 & 400 \\
\hline & 1.5 & 96.4 & 96.8 & 52.1 & 52.2 & 400 & 400 \\
\hline \multirow{4}{*}{$q_{2}$} & 0 & 63.4 & 63.6 & NA & NA & 350 & 350 \\
\hline & 0.5 & 138.1 & 138.3 & 117.8 & 117.5 & 400 & 400 \\
\hline & 1.0 & 136.8 & 137.1 & 115.8 & 115.6 & 400 & 400 \\
\hline & 1.5 & 149.9 & 150.0 & 136.4 & 135.8 & 400 & 400 \\
\hline
\end{tabular}

Table 13. Maximum von Mises stresses and times at which they occur in tile for the square configurations using previous assumptions

\begin{tabular}{|c|c|c|c|c|c|c|c|}
\hline \multirow{2}{*}{$\begin{array}{l}\text { Thermal } \\
\text { Loading }\end{array}$} & \multirow[t]{2}{*}{$\begin{array}{c}D \\
\text { (inch) }\end{array}$} & \multicolumn{2}{|c|}{$\begin{array}{c}\text { Max. von Mises stress } \\
\text { (kPa) }\end{array}$} & \multicolumn{2}{|c|}{$\%$ change } & \multicolumn{2}{|c|}{$\begin{array}{c}\text { Time } \\
\text { (s) }\end{array}$} \\
\hline & & BC1 & BC2 & BC1 & BC2 & BC1 & BC2 \\
\hline \multirow{4}{*}{$q_{1}$} & 0 & 30.1 & 4.61 & NA & NA & 7150 & 6050 \\
\hline & 0.5 & 30.0 & 4.31 & -0.3 & -6.5 & 7250 & 5600 \\
\hline & 1.0 & 29.0 & 4.20 & -3.7 & -8.9 & 7200 & 5450 \\
\hline & 1.5 & 27.6 & 3.94 & -8.3 & -14.5 & 7000 & 5150 \\
\hline \multirow{4}{*}{$q_{2}$} & $\overline{00}$ & 30.1 & 4.61 & $\overline{\mathrm{NA}}$ & NA & 7150 & 6050 \\
\hline & 0.5 & 31.8 & 4.65 & 5.6 & 0.9 & 7200 & 5900 \\
\hline & 1.0 & 37.3 & 5.45 & 23.9 & 18.2 & 6800 & 5700 \\
\hline & 1.5 & 47.7 & 6.99 & 58.5 & 51.6 & 6350 & 5250 \\
\hline
\end{tabular}

Table 14. Maximum von Mises stresses and times at which they occur in SIP for the square configurations using previous assumptions

\begin{tabular}{|c|c|c|c|c|c|c|c|}
\hline \multirow{2}{*}{$\begin{array}{l}\text { Thermal } \\
\text { Loading }\end{array}$} & \multirow{2}{*}{$\begin{array}{c}D \\
\text { (inch) }\end{array}$} & \multicolumn{2}{|c|}{$\begin{array}{c}\text { Max. von Mises stress } \\
\text { (MPa) }\end{array}$} & \multicolumn{2}{|c|}{ \% change } & \multicolumn{2}{|c|}{$\begin{array}{c}\text { Time } \\
\text { (s) }\end{array}$} \\
\hline & & BC1 & BC2 & BC1 & BC2 & BC1 & BC2 \\
\hline \multirow{4}{*}{$q_{1}$} & 0 & 2.32 & 283.1 & NA & NA & 7300 & 7150 \\
\hline & 0.5 & 2.34 & 277.9 & 0.8 & -1.8 & 7300 & 7150 \\
\hline & 1.0 & 2.26 & 268.6 & -2.6 & -5.1 & 7250 & 7100 \\
\hline & 1.5 & 2.16 & 255.5 & -6.9 & -9.7 & 7100 & 6900 \\
\hline \multirow{4}{*}{$q_{2}$} & 0 & 2.32 & 283.1 & NA & NA & 7300 & 7150 \\
\hline & 0.5 & 2.48 & 294.6 & 6.9 & 4.1 & 7300 & 7100 \\
\hline & 1.0 & 2.91 & 345.5 & 25.4 & 22.0 & 6900 & 6850 \\
\hline & 1.5 & 3.73 & 442.3 & 60.8 & 56.2 & 6450 & 6300 \\
\hline
\end{tabular}

Table 15. Maximum von Mises stresses and times at which they occur in underlying structure for the square configurations using previous assumptions 


\begin{tabular}{||c||c||c|c||c|c||c|c||}
\hline \hline \multirow{2}{*}{$\begin{array}{c}\text { Thermal } \\
\text { Loading }\end{array}$} & \multirow{2}{*}{$\begin{array}{c}\boldsymbol{D} \\
\text { (inch) }\end{array}$} & \multicolumn{2}{c||}{$\begin{array}{c}\text { Max. von Mises stress } \\
\text { (kPa) }\end{array}$} & \multicolumn{2}{c|}{ \% change } & \multicolumn{2}{c|}{$\begin{array}{c}\text { Time } \\
\text { (s) }\end{array}$} \\
\cline { 2 - 8 } & & BC1 & BC2 & BC1 & BC2 & BC1 & BC2 \\
\hline \hline \multirow{3}{*}{$q_{1}$} & 0 & 64.9 & 65.0 & NA & NA & 200 & 200 \\
\cline { 2 - 8 } & 0.5 & 111.7 & 112.0 & 72.1 & 72.3 & 250 & 250 \\
\cline { 2 - 8 } & 1.0 & 105.3 & 105.5 & 62.2 & 62.3 & 250 & 250 \\
\cline { 2 - 8 } & 1.5 & 96.3 & 96.5 & 48.4 & 48.5 & 250 & 250 \\
\hline \hline \multirow{3}{*}{$q_{2}$} & 0 & 64.9 & 65.0 & NA & NA & 200 & 200 \\
\cline { 2 - 8 } & 0.5 & 96.4 & 96.6 & 48.5 & 48.6 & 400 & 400 \\
\cline { 2 - 8 } & 1.0 & 119.1 & 119.3 & 83.5 & 83.5 & 400 & 400 \\
\cline { 2 - 8 } & 1.5 & 132.2 & 132.4 & 103.7 & 103.7 & 400 & 400 \\
\hline \hline
\end{tabular}

Table 16. Maximum von Mises stresses and times at which they occur in tile for the square configurations using new assumptions

\begin{tabular}{||c||c||c|c||c|c||c|c||}
\hline \hline \multirow{2}{*}{$\begin{array}{c}\text { Thermal } \\
\text { Loading }\end{array}$} & \multirow{2}{*}{$\begin{array}{c}\boldsymbol{D} \\
\text { (inch) }\end{array}$} & \multicolumn{2}{c|}{$\begin{array}{c}\text { Max. von Mises stress } \\
\text { (kPa) }\end{array}$} & \multicolumn{2}{c||}{ \% change } & \multicolumn{2}{c|}{$\begin{array}{c}\text { Time } \\
\text { (s) }\end{array}$} \\
\cline { 2 - 8 } & & BC1 & BC2 & BC1 & BC2 & BC1 & BC2 \\
\hline \hline \multirow{3}{*}{$q_{1}$} & 0 & 32.2 & 3.08 & NA & NA & 5450 & 5500 \\
\cline { 2 - 8 } & 0.5 & 31.9 & 3.05 & -0.9 & -1.0 & 5450 & 5500 \\
\cline { 2 - 8 } & 1.0 & 30.9 & 2.96 & -4.0 & -3.9 & 5400 & 5450 \\
\cline { 2 - 8 } & 1.5 & 29.5 & 2.85 & -8.4 & -7.5 & 5300 & 5350 \\
\hline \hline \multirow{3}{*}{$q_{2}$} & 0 & 32.2 & 3.08 & NA & NA & 5450 & 5500 \\
\cline { 2 - 8 } & 0.5 & 36.8 & 3.51 & 14.3 & 14.0 & 5350 & 5400 \\
\cline { 2 - 8 } & 1.0 & 56.7 & 5.38 & 76.1 & 74.7 & 4950 & 5000 \\
\cline { 2 - 8 } & 1.5 & 96.7 & 8.89 & 200.3 & 188.6 & 4200 & 4250 \\
\hline
\end{tabular}

Table 17. Maximum von Mises stresses and times at which they occur in SIP for the square configurations using new assumptions

\begin{tabular}{||c||c||c|c||c|c||c|c||}
\hline \multirow{2}{*}{$\begin{array}{c}\text { Thermal } \\
\text { Loading }\end{array}$} & \multirow{2}{*}{$\begin{array}{c}\boldsymbol{D} \\
\text { (inch) }\end{array}$} & \multicolumn{2}{c|}{$\begin{array}{c}\text { Max. von Mises stress } \\
\text { (MPa) }\end{array}$} & \multicolumn{2}{c|}{ \% change } & \multicolumn{2}{c|}{$\begin{array}{c}\text { Time } \\
\text { (s) }\end{array}$} \\
\cline { 2 - 8 } & & BC1 & BC2 & BC1 & BC2 & BC1 & BC2 \\
\hline \hline \multirow{3}{*}{$q_{\mathbf{1}}$} & 0 & 1.86 & 308.9 & NA & NA & 5550 & 5450 \\
\cline { 2 - 8 } & 0.5 & 1.84 & 305.9 & -1.1 & -1.0 & 5550 & 5450 \\
\cline { 2 - 8 } & 1.0 & 1.79 & 297.0 & -3.8 & -3.9 & 5500 & 5400 \\
\cline { 2 - 8 } & 1.5 & 1.72 & 284.9 & -7.5 & -7.8 & 5400 & 5300 \\
\hline \hline \multirow{3}{*}{$q_{\mathbf{2}}$} & 0 & 1.86 & 308.9 & NA & NA & 5550 & 5450 \\
\cline { 2 - 8 } & 0.5 & 2.11 & 347.0 & 13.4 & 12.3 & 5450 & 5350 \\
\cline { 2 - 8 } & 1.0 & 3.09 & 476.5 & 66.1 & 54.3 & 5050 & 4950 \\
\cline { 2 - 8 } & 1.5 & 4.88 & 688.8 & 162.4 & 123.0 & 4250 & 4200 \\
\hline
\end{tabular}

Table 18. Maximum von Mises stresses and times at which they occur in underlying structure for the square configurations using new assumptions 


\begin{tabular}{|c|c|c|c|}
\hline $\begin{array}{c}\text { TPS } \\
\text { Component }\end{array}$ & $\begin{array}{c}\text { Max. temperatures with } \\
\delta=0 "\left({ }^{\circ} \mathrm{C}\right) \\
\end{array}$ & $\begin{array}{l}\text { Max. temperatures with } \\
\qquad \delta=1 ” \quad\left({ }^{\circ} \mathrm{C}\right) \\
\end{array}$ & $\begin{array}{c}\text { Max. temperature with } \\
\qquad \delta=2 "\left({ }^{\circ} \mathrm{C}\right) \\
\end{array}$ \\
\hline LI-900 & 2048 & 2080 & 2100 \\
\hline SIP & 242 & 244 & 241 \\
\hline Structure & 241 & 241 & 237 \\
\hline
\end{tabular}

Table 19. Maximum temperature attained for each TPS component for different $\delta$ with $q_{2}$ loading.

\begin{tabular}{||c|c|c|c|c||}
\hline \hline $\begin{array}{c}\text { Structural } \\
\text { BC }\end{array}$ & $\begin{array}{c}\text { TPS } \\
\text { Component }\end{array}$ & $\begin{array}{c}\text { Max. von Mises } \\
\text { Stress with } \boldsymbol{\delta}=\mathbf{0} \text { ” } \\
\mathbf{( P a )}\end{array}$ & $\begin{array}{c}\text { Max. von Mises } \\
\text { Stress with } \boldsymbol{\delta}=\mathbf{1} \text { ” } \\
\mathbf{( P a )}\end{array}$ & $\begin{array}{c}\text { Max. von Mises } \\
\text { Stress with } \boldsymbol{\delta}=\mathbf{2} \text { ” } \\
\mathbf{( P a )}\end{array}$ \\
\hline \multirow{3}{*}{ BC1 } & LI-900 & $1.19 \times 10^{5}$ & $1.12 \times 10^{5}$ & $1.14 \times 10^{5}$ \\
\cline { 2 - 5 } & SIP & $2.96 \times 10^{3}$ & $2.96 \times 10^{3}$ & $2.96 \times 10^{3}$ \\
\cline { 2 - 5 } & Structure & $2.97 \times 10^{8}$ & $2.98 \times 10^{8}$ & $2.98 \times 10^{8}$ \\
\hline \multirow{3}{*}{ BC2 } & LI-900 & $1.19 \times 10^{5}$ & $1.14 \times 10^{5}$ & $9.37 \times 10^{4}$ \\
\cline { 2 - 5 } & SIP & $5.38 \times 10^{3}$ & $5.37 \times 10^{3}$ & $5.27 \times 10^{3}$ \\
\cline { 2 - 5 } & Structure & $4.77 \times 10^{8}$ & $4.76 \times 10^{8}$ & $4.71 \times 10^{8}$ \\
\hline
\end{tabular}

Table 20. Maximum von Mises stresses attained for each TPS component for BC1 and BC2 boundary conditions

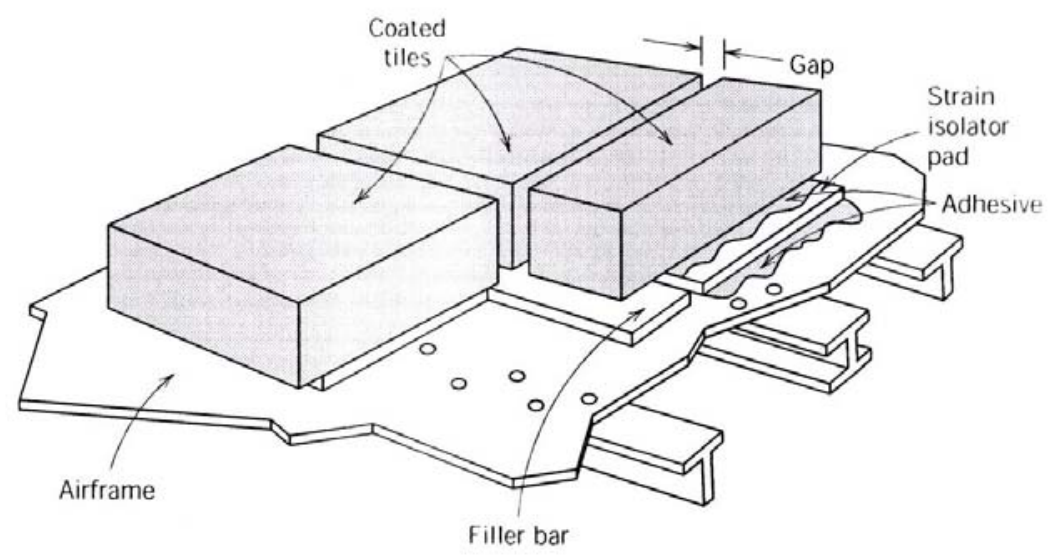

Figure 1. Space Shuttle TPS and Airframe (Callister, W.D., "Materials Science and Engineering: An introduction”, John Wiley and Sons Inc., New York, 2003, Pg. S-349)

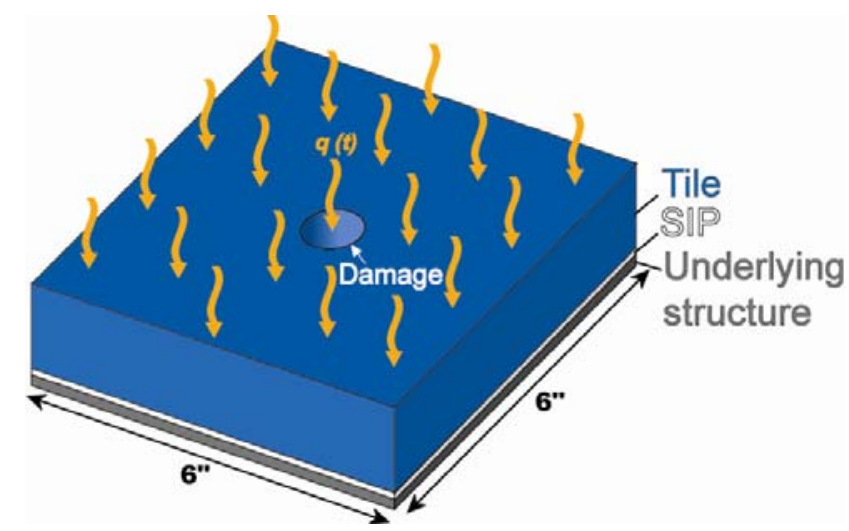

Figure 2. Schematic view of square segment of the three-layered TPS configuration 


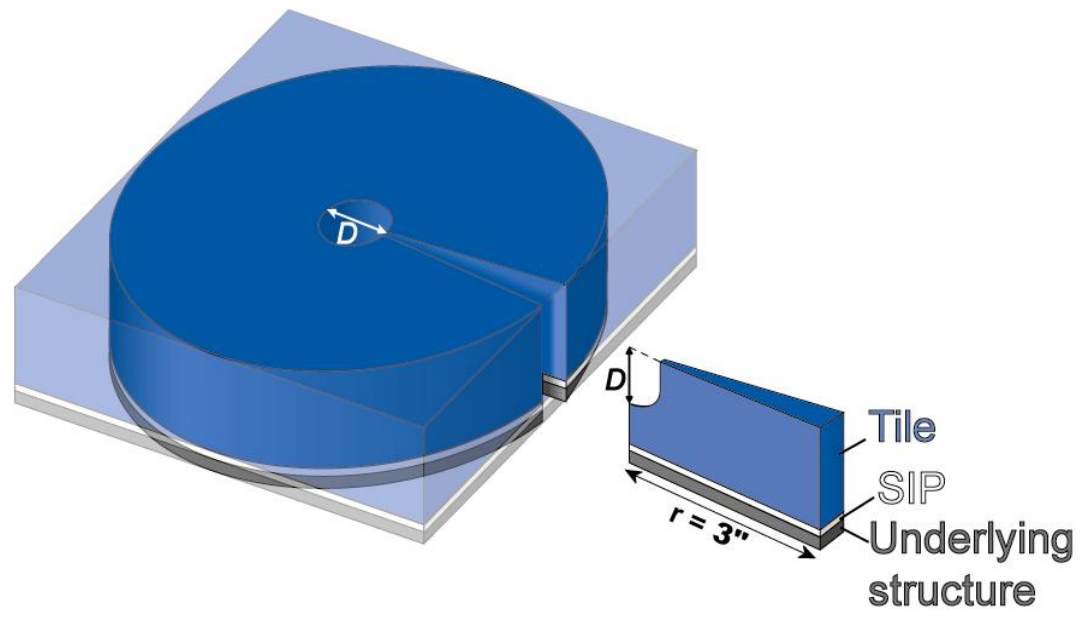

Figure 3. Circular axisymmetric configuration

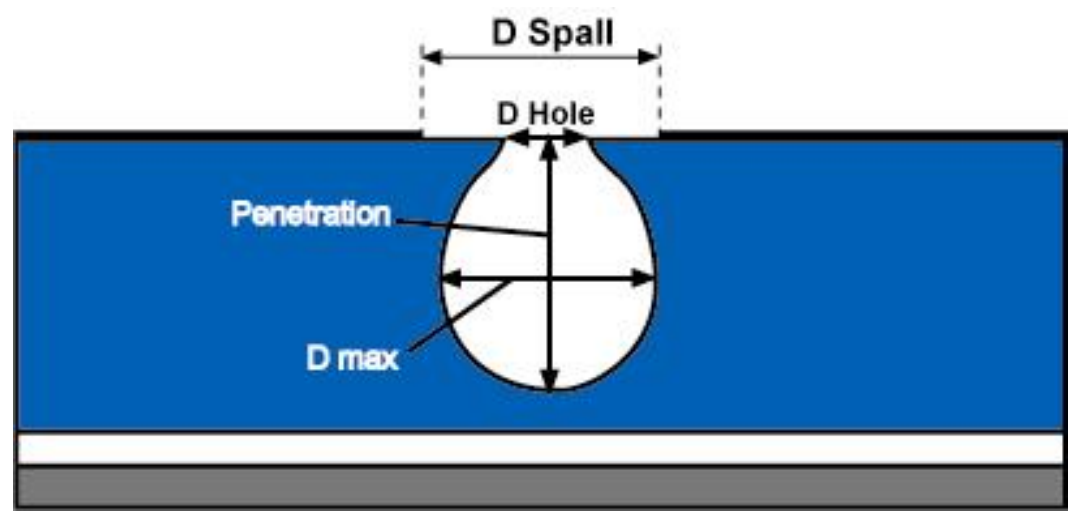

Figure 4. Damage geometry associated with hypervelocity impact.

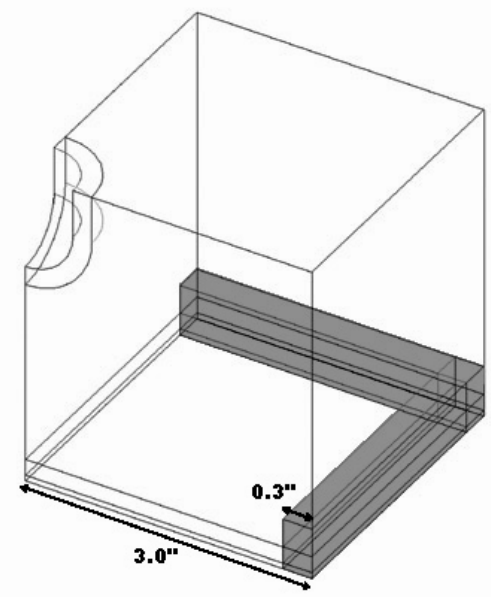

Figure 5. Square configuration illustrating the boundary layer region in the thermal stress analysis 


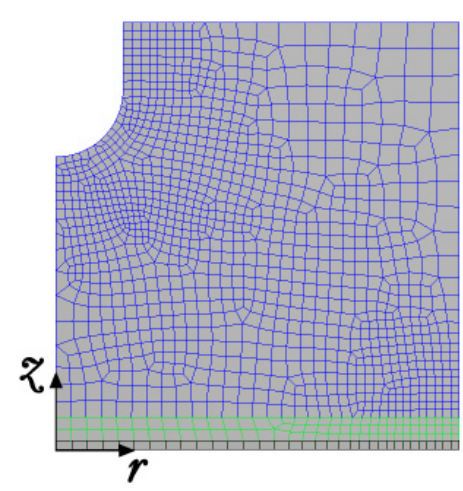

(a) Axisymmetric configuration for $D=1$ ” damage system

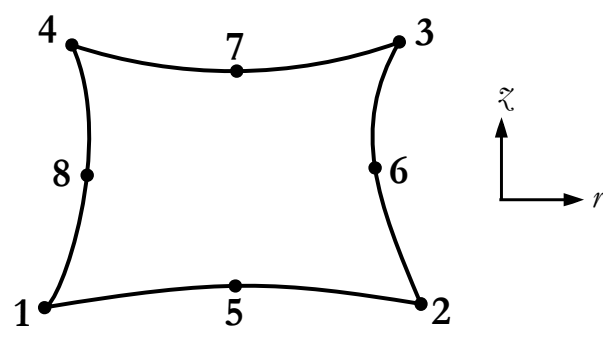

(b) 8-node biquadratic element used for axisymmetric configuration

Figure 6. Schematic representation of the axisymmetric configuration with damage at the center

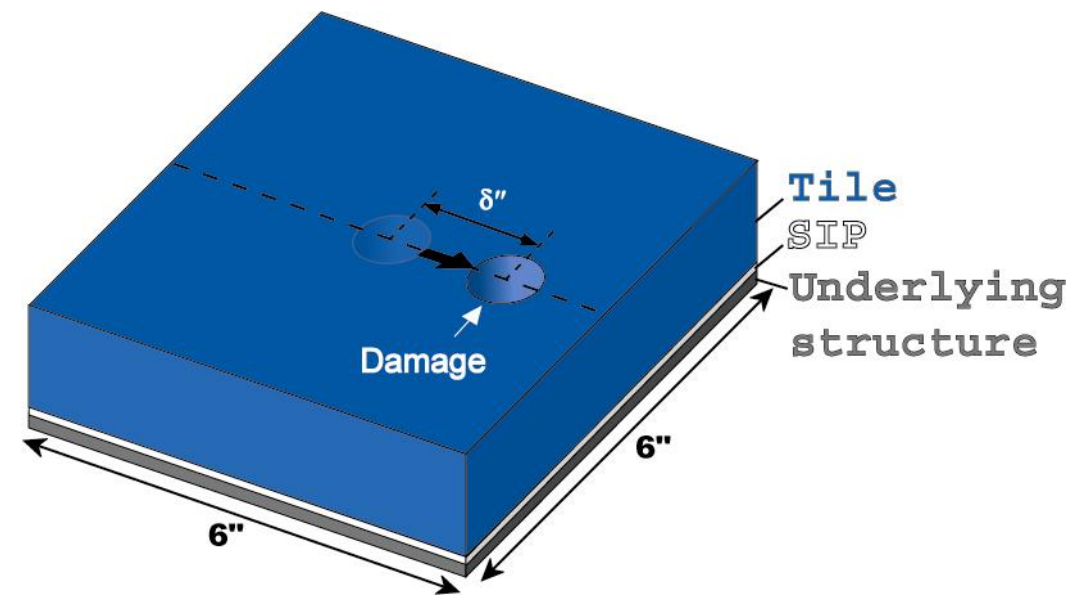

Figure 7. Schematic of square configuration illustrating the change in location of damage from center

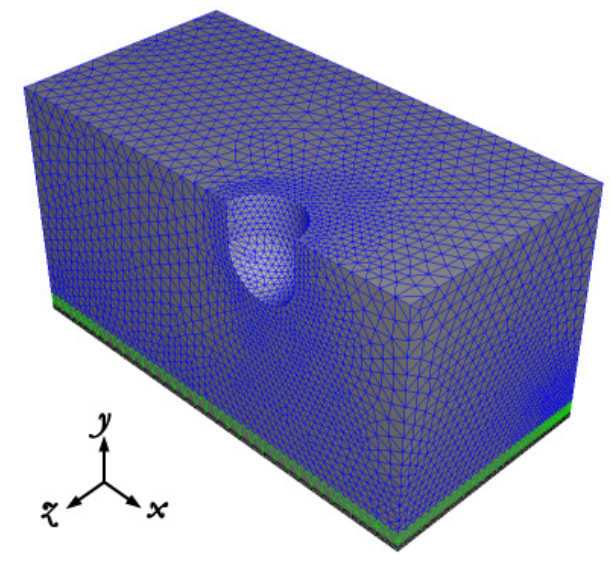

(a) Square configuration for $D=1$ " damage system with

$$
\delta=1 ”
$$

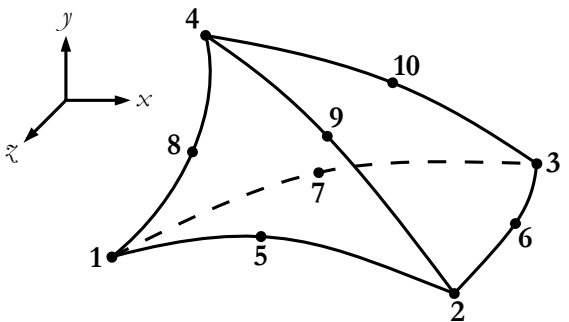

(b) 10 node quadratic tetrahedron element used for square configuration

Figure 8. Schematic representation of the square configuration with damage located 1" from center 


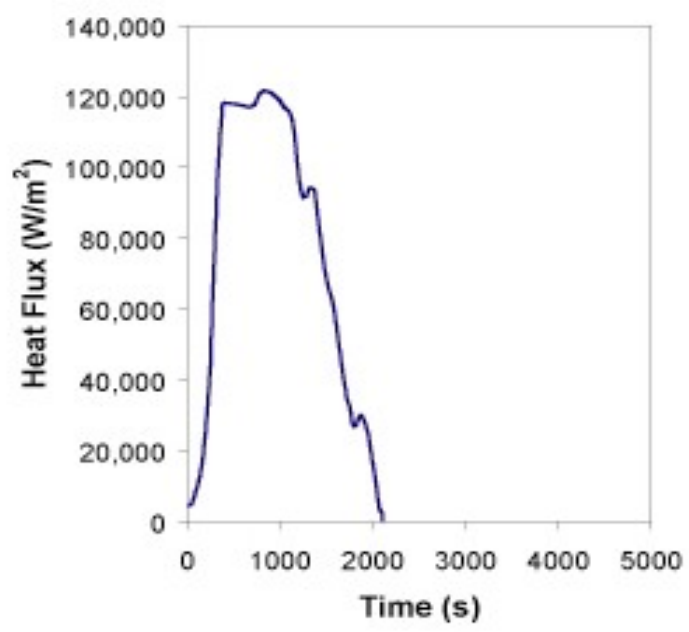

Figure 9. Re-entry heat flux loading profile for the ATS vehicle, $q_{\text {ATS }}$

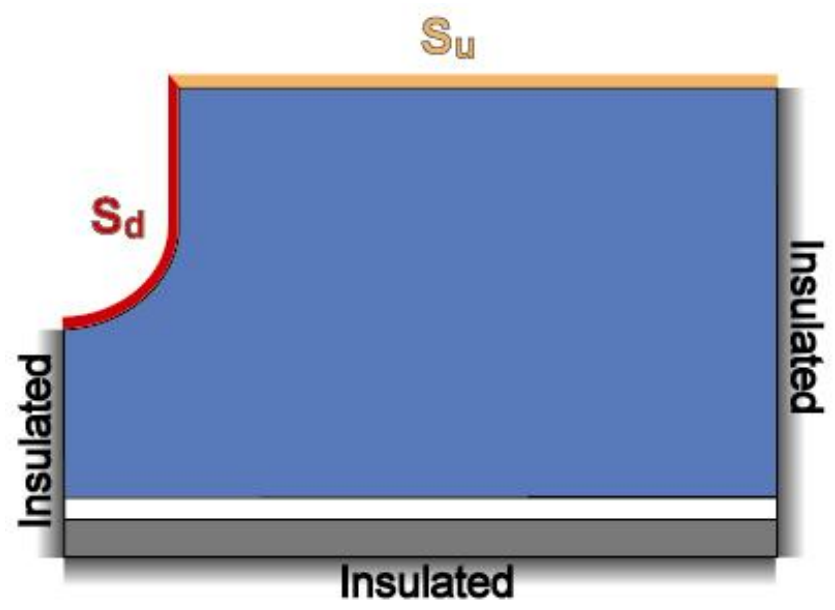

Figure 10. Cross section of TPS showing the undamaged and damaged surfaces subjected to thermal loading

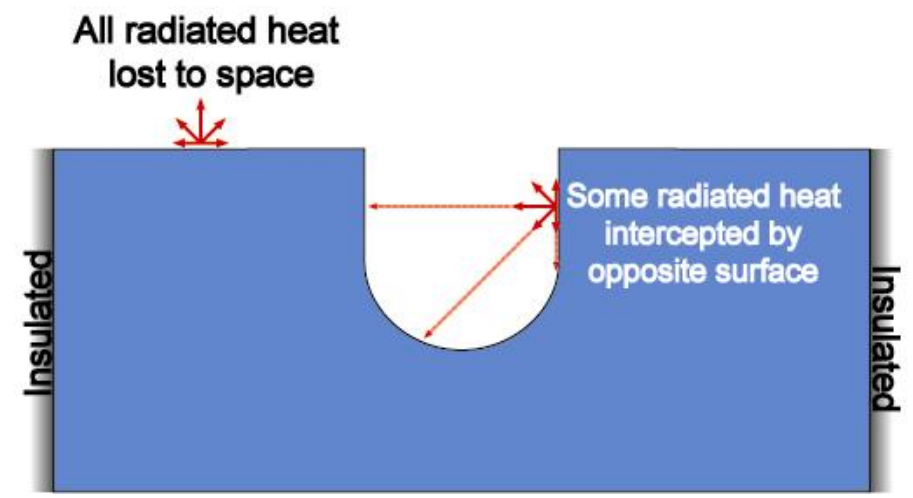

Figure 11. Schematic representation of radiation heat loss in the tile 


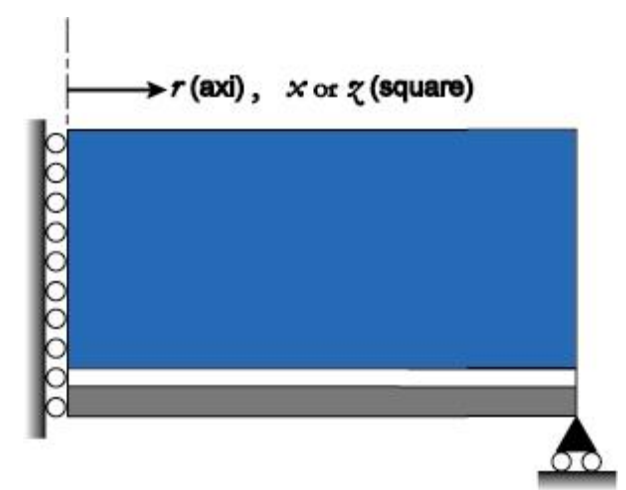

(a) unrestrained boundary condition, BC1

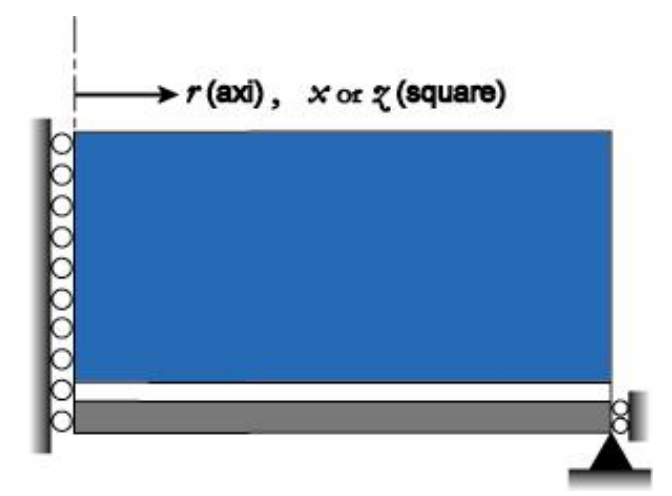

(b) restrained boundary condition, BC2

Figure 12. Structural boundary conditions applied to underlying structure

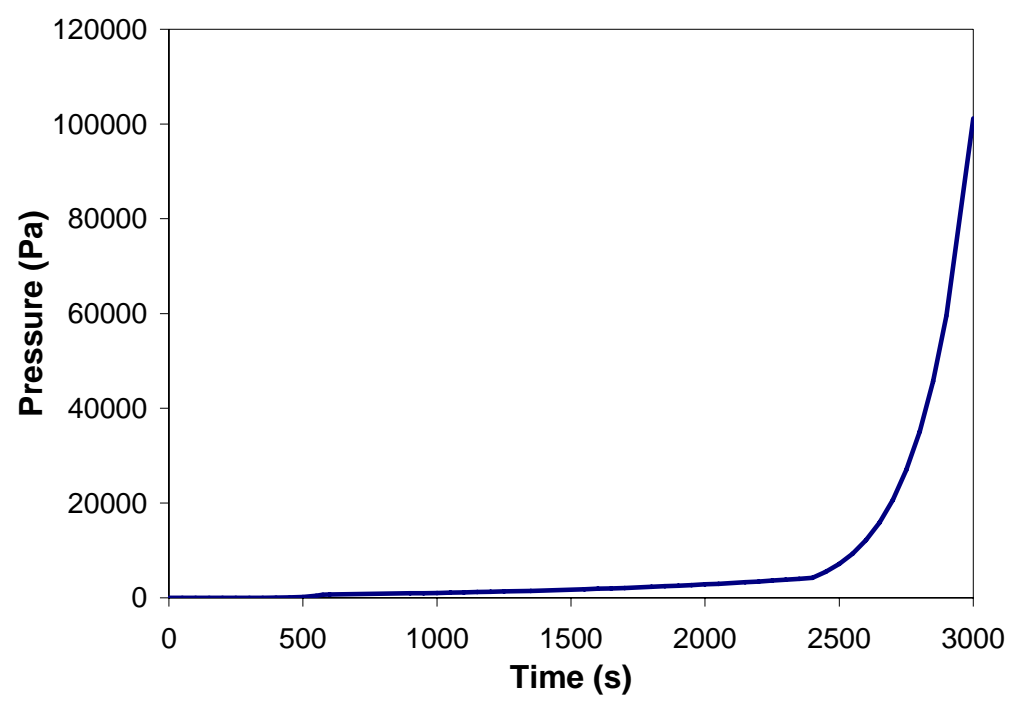

Figure 13: Operating pressure profile used in analysis 


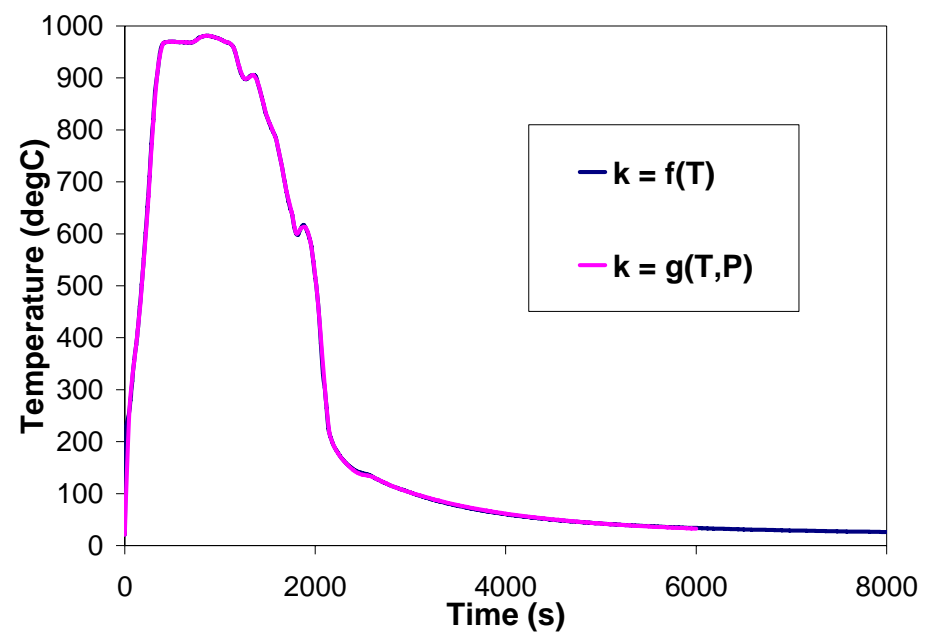

(a) Surface of tile

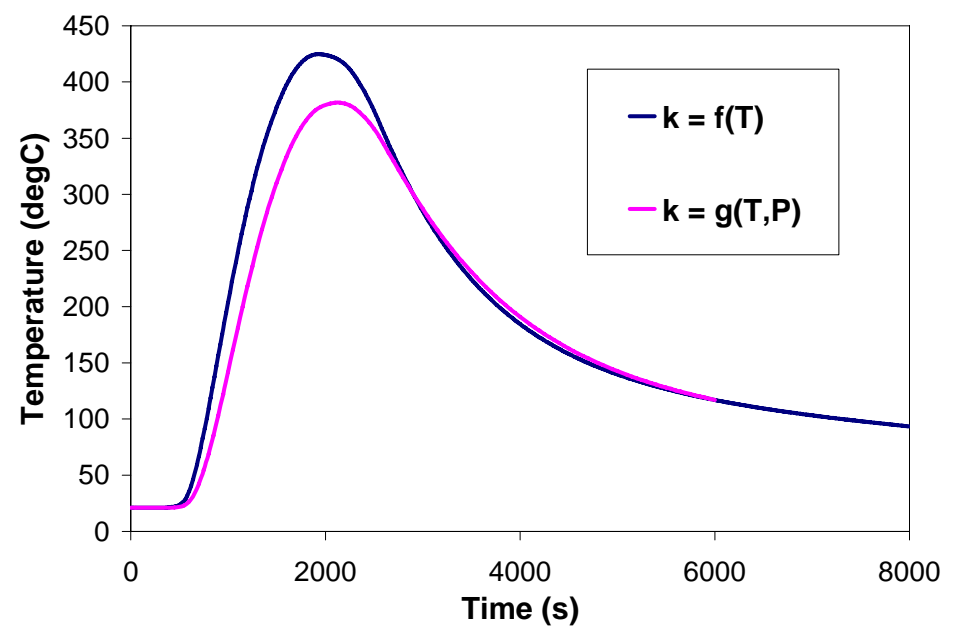

(b) Middle of tile

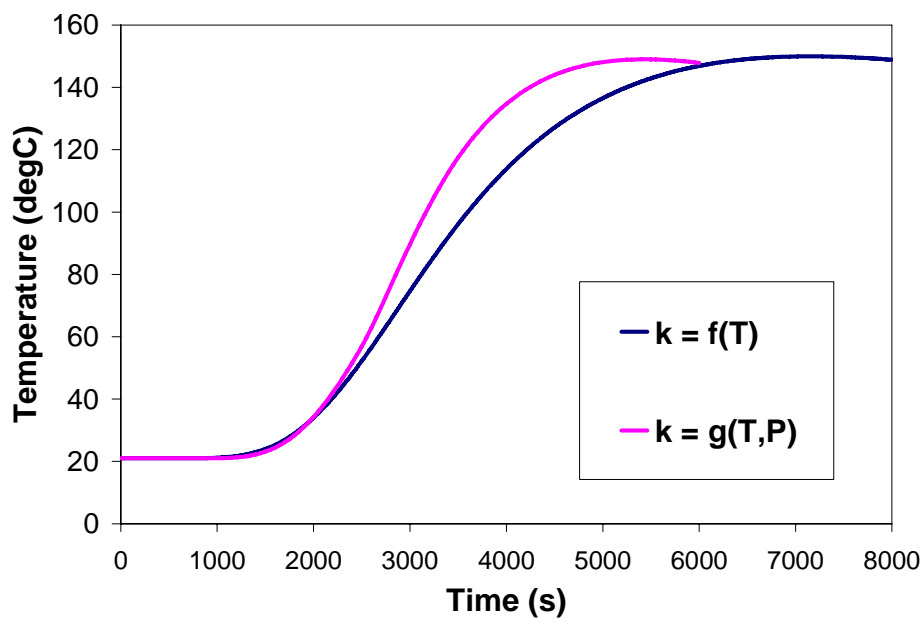

(c) Underlying structure

Figure 14: Transient temperature results at the surface and middle of the tile and at underlying structure for analyses with and without pressure dependent conductivity 


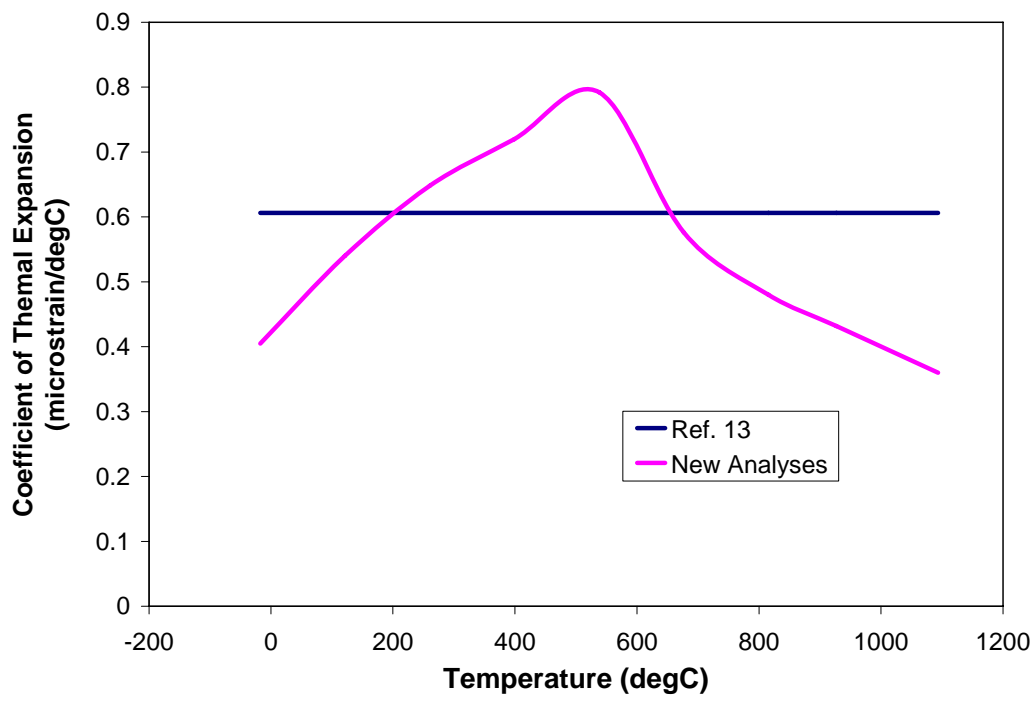

Figure 15. CTE with respect to temperature used in Ref. 13 and the new analyses 